\title{
Effects of Moringa oleifera Seed Oil on Acetaminophen-Induced Oxidative Stress and Liver Damage in Wistar Albino Rats
}

\author{
Olatosin T. M. ${ }^{1}$, Akinduko D. S. ${ }^{2 *}$, Uche C. Z. ${ }^{2}$, Bardi J. ${ }^{1}$ \\ ${ }^{I}$ Department of Biochemistry, Faculty of Life Sciences, University of Benin, Benin City, Nigeria. \\ ${ }^{2}$ Department of Chemical Pathology, College of Medicine, University of Ibadan, Ibadan, Nigeria.
}

\begin{abstract}
The aim of the present study was to investigate the effects of Moringa oleifera seed oil against acetaminophen-induced liver injury. 24 male Wistar albino rats were distributed into four treatment groups of six animals each and treatment lasted for ten days. Group1 animals were the Controls while the group2 animals received acetaminophen dosage (1g/Kg body weight) only on the tenth day. Group3 animals received oral administration of Moringa oleifera seed oil $(2 \mathrm{ml} / \mathrm{kg}$ weight) also for 10days prior to being treated with acetaminophen $(1 \mathrm{~g} / \mathrm{kg}$ body weight) on the tenth day. Group4 animals were administered only with the seed oil for ten days. Plasma activities of liver marker enzymes ALT and ALP were significantly lower ( $p<0.05)$ in animals pre-treated with Moringa oil, compared with those treated with only acetaminophen. Likewise, oral pre-treatment with the oil resulted in a marked reduction in the severity of liver injury, with hepatic MDA formation significantly lower $(p<0.05)$ in group3 animals compared with those in group2. Furthermore, histological examination of the liver tissues revealed changes consistent with the reported biochemical findings. These results suggest that Moringa oleifera seed oil contains natural antioxidants which are believed to mediate its hepatoprotective effects.
\end{abstract}

Keywords: Liver Injury, Acetaminophen-induced, Moringa Seed Oil, Treatment, Hepatoprotective

\section{Introduction}

Liver is the largest organ of the human body weighing approximately $1500 \mathrm{~g}$, and is located in the upper right corner of the abdomen on top of the stomach, right kidney and intestines and beneath the diaphragm [1]. The liver is prone to xenobiotic-induced injury because of its central role in xenobiotic metabolism, its portal location within the circulation, and its anatomic and physiologic structure [2]. Due to the important role the liver plays in biotransformation of drugs and toxins, drug-induced hepatotoxicity should be a major concern in drug development and chronic drug therapy [1]. Hepatotoxicity can be characterized into two main groups, each with a different mechanism of injury: hepatocellular and cholestatic [3]. A hepatocellular pattern is marked by isolated or predominant elevations of serum transaminases [4]. On the other hand, cholestatic injury is characterized by predominantly initial alkaline phosphatase level elevations that precede or are relatively more prominent than increases in the levels serum transaminases [1]. Generally mixed type of injuries, involving both hepatocellular and cholestatic mechanisms, occurs [5].

Chemical agents that cause liver injury are otherwise called hepatotoxins. Main patterns of liver injury during hepatotoxicity may include zonal necrosis, hepatitis, cholestasis, steatosis, granuloma, vascular lesions, neoplasm and veno-occlusive diseases [1]. Hepatotoxicity and drug-induced liver injury also account for a substantial number of compound failures, highlighting the need for drug screening assays, such as stem cellderived hepatocyte-like cells, that are capable of detecting toxicity early in the drug development process [6]. More than 900 drugs have been implicated in causing liver injury [7] and this is the most common reason for a drug withdrawal from the market.

Acetaminophen is a widely used analgesic and antipyretic drug [8], usually well-tolerated in prescribed dose but overdose is the most common cause of drug-induced hepatotoxicity worldwide [1]. The drug Acetaminophen is commonly known as paracetamol. Damage to the liver is not due to the drug itself, but to a toxic metabolite, N-acetyl-p-benzoquinone imine (NABQI), which is produced by cytochrome P-450 enzymes in the liver [9]. These drug-metabolizing enzymes detoxify many xenobiotics but activate the toxicity of others [10]. An overdose of the analgesic drug acetaminophen can lead to severe liver injury in humans and in experimental animals; although the mechanism of this injury is still not entirely clear [10]. According to Singh et al. [1], the toxic metabolite NAPQI (otherwise called NABQI) forms a covalent adduct with mitochondrial proteins having thiol groups and plasma membrane proteins involved in calcium homeostasis. Disruption of calcium homeostasis may result in the activation of many membrane damaging enzymes like ATPases, phospholipases, proteases and endonucleases, disruption of mitochondrial metabolism and ATP synthesis and damage of microfilaments used to support cell structure [1].

Drug-induced injury to hepatocytes and bile duct cells can lead to cholestasis; this in turn causes intrahepatic accumulation of toxic bile acids and excretion products, which promotes further hepatic injury [10]. 
Liver injury can be diagnosed by certain biochemical markers like alanine aminotransferase (ALT), aspartate aminotransferase (AST), alkaline phosphatase (ALP) and bilirubin [1]. The elevation of serum activities of hepatocellular enzymes ALT, AST and ALP is a reflection of their increased passage into the serum from damaged liver cells [11]. Serum alkaline phosphatase increases to some extent in most types of liver injury [12]. Bile acids account for this increase: they induce alkaline phosphatase synthesis and exert a detergent effect on the canalicular membrane, allowing leakage into serum $[13,14]$. The highest concentrations are observed with cholestatic injuries [15].

Significant amount of evidence has pointed to the potential involvement of oxidative stress in acetaminophen toxicity [16]. For instance, toxicity of acetaminophen was reportedly decreased after the administration of encapsulated superoxide dismutase (SOD) in the rat [17]. It is therefore against this backdrop that lipid peroxidation has been suggested to play a key role in the pathophysiology of acetaminophen-induced liver injury, but the exact mechanism remains yet unraveled. Malondialdehyde (MDA) is one of the most frequently measured biomarkers of oxidative stress in an organism.

The use of and search for drugs and dietary supplements derived from plants have accelerated in recent years [18]. Medicinal properties of plants have also been investigated in the light of recent scientific developments throughout the world, due to their potent pharmacological activities, low toxicity and economic viability, when compared with synthetic drugs [19]. Therefore, owing to its vast medicinal potentials, Moringa oleifera plant has recently gained much attention. Although native to South Asia (particularly India), Moringa oleifera plant is now widely cultivated across Nigeria and almost the entire West African sub-region. Moringa oleifera is the best known of the thirteen species in the genus Moringa of Family Moringaceae; these are Moringa oleifera, M. arborea, M. borziana, M. concanensis, M. drouhardii, M. hildebrandtii, M. longituba, M. ovalifolia, M. peregrine, M. pygmaea, M. rivae, M. ruspoliana and Mstenopetala [20]. Moringa oleifera is coming to the forefront as a result of scientific evidence that Moringa is an important source of naturally occurring phytochemicals and this provides a basis for future viable developments [21].

Almost all the parts of this plant: root, bark, gum, leaf, fruit (pods), flowers, seed and seed oil have been used for various ailments in the indigenous medicine of South Asia, including the treatment of inflammation and infectious diseases along with cardiovascular, gastrointestinal, hematological and hepatorenal disorders [22]. The healing properties of Moringa oil have been documented by ancient cultures [21]. So far, the hepatoprotective efficacy of Moringa oleifera seed oil has remained largely under-exploited, hence the need for intensive research in order to justify earlier evidences in this regard. The main objective of this study was therefore to evaluate the protective effect of Moringa oleifera seed oil against acetaminophen-induced hepatotoxicity in Wistar albino rats.

\subsection{Experimental Animals}

\section{Materials and Methods}

A total of 24 male albino rats (Wistar, 150-180g) purchased from Animal Science Department of the University of Ibadan (Nigeria) were divided into four (4) groups: Control, Acetaminophen, Acetaminophen+Moringa oil, and Moringa oil-treated; each group contains six animals. The animal house was kept under standardized conditions and the animals had free access to food (grower's mash) and distilled water for two weeks before treatments commenced.

\subsection{Moringa Seed Oil (Extract)}

The Moringa oil taken as the extract was obtained from Millenium Quality Oil Factory, Gombe, Gombe State, Nigeria.

\subsection{Treatment Regimen}

\begin{tabular}{|l|l|}
\hline \multicolumn{1}{|c|}{ GROUP } & \multicolumn{1}{|c|}{ DOSAGE ADMINISTERED } \\
\hline 1. Control & - \\
\hline 2. Acetaminophen Only & $1 \mathrm{~g}$ Acetaminophen/kg body weight once (on the 10th day) \\
\hline 3. Acetaminophen + Oil & $\begin{array}{l}2 \mathrm{ml} \text { of Moringa oil/Kg body weight for } 10 \text { days and administration of Acetaminophen } \\
(1 \mathrm{ml} / \mathrm{Kg}) \text { once (after } 12 \text { hrs on the } 10 \text { th day) }\end{array}$ \\
\hline 4. Oil Only & $2 \mathrm{ml}$ of Moringa oil/Kg body weight for 10 days \\
\hline
\end{tabular}

The animals were sacrificed 24 hours after the tenth day treatment; blood samples were collected via cardiac puncture into lithium heparin anticoagulant bottles for plasma biochemical assays. Liver tissues were also excised and preserved for histological analysis. 


\subsection{Preparation of Liver Tissue Homogenates for Biochemical Assays}

The liver tissue of each rat was homogenized in $5 \mathrm{ml}$ normal saline solution with the aid of mortal and piston. The solution was poured into a labeled test tube and centrifuged at $3000 \mathrm{ppm}$ for 15 minutes. The supernatant was collected and stored at $4^{0} \mathrm{C}$ in a refrigerator.

\subsubsection{Determination of Hepatic Malondialdehyde (MDA) Level}

MDA, a product of lipid peroxidation, when heated with 2-thiobarbituric acid (under acidic condition) forms an orange-pink colour product which has a maximum absorbance at $535 \mathrm{~nm}$. The assay method of Beuge and Aust [23] was adopted.

Procedure:

$>0.5 \mathrm{ml}$ of tissue homogenate was pipetted into test tubes (to aid heating).

$>$ A stock solution of trichloroacetic acid (TCA), thiobarbituric acid (TBA) and Hydrochloric acid ( $\mathrm{HCl}$ ) containing $15 \mathrm{~g}$ TCA, $0.375 \mathrm{~g}$ TBA and $0.25 \mathrm{~N} \mathrm{HCl}$ was prepared.

$>2 \mathrm{ml}$ of TBA-TCA-HCl reagent was added to the various tubes.

$>$ The tubes were vigorously shaken and heated for fifteen minutes in a water bath at $100^{\circ} \mathrm{C}$, then allowed to cool.

$>$ The various solutions were centrifuged and the supernatant were collected.

$>$ The absorbance of the orange-pink coloured product was read at $535 \mathrm{~nm}$.

\subsubsection{Determination of Hepatic Superoxide Dismutase (SOD) Activity}

The assay of SOD in the liver was determined by the method of Misra and Fredovich [24].

Procedure:

$>$ An aliquot, $0.4 \mathrm{ml}$ of the diluted supernatant of the tissue homogenate was added to $5 \mathrm{ml}$ of $0.05 \mathrm{M}$ carbon buffer, $\mathrm{pH} 10.2$ to equilibrate in the spectrophotometer and the reaction started by the addition of $0.6 \mathrm{mls}$ of freshly prepared $0.3 \mathrm{mM}$ epinephrine as the substrate to the buffer supernatant mixture, which was quickly mixed by inversion.

$>$ The reference cuvette contains $5 \mathrm{ml}$ of the buffer, $0.6 \mathrm{mls}$ of the adrenaline and $0.4 \mathrm{mls}$ of distilled water. The increase in absorbance at $480 \mathrm{~nm}$ due to the adrenochrome formed was monitored every 30 seconds for 120 seconds.

$>$ One unit of SOD activity was given as the amount of SOD necessary to cause 50\% inhibition of the oxidation of epinephrine to adrenochrome during 60seconds.

\subsubsection{Determination of Catalase (CAT) Activity}

Catalase enzyme prevents the accumulation of $\mathrm{H}_{2} \mathrm{O}_{2}$ by converting it to $\mathrm{H}_{2} \mathrm{O}_{2}$ by converting it to $\mathrm{H}_{2} \mathrm{O}$ and $\mathrm{O}_{2}$. Potassium permanganate is a powerful oxidizing agent that can decompose certain compounds. $\mathrm{KMnO}_{4}$ decomposes hydrogen peroxide through the following reaction [25]

$\mathrm{H}_{2} \mathrm{O}_{2} \longrightarrow 2 \mathrm{H}_{2} \mathrm{O}+\mathrm{O}_{2}$

$5 \mathrm{H}_{2} \mathrm{O}_{2}+2 \mathrm{KMnO}_{4}+3 \mathrm{H}_{2} \mathrm{SO}_{4} \longrightarrow \mathrm{K}_{2} \mathrm{SO}_{4}+2 \mathrm{MnSO}_{4}+8 \mathrm{H}_{2} \mathrm{O}+5 \mathrm{O}_{2}$

$>0.5 \mathrm{ml}$ aliquot of the liver homogenate was added to ice cold tubes.

$>$ Reaction was started by adding $5 \mathrm{ml}$ of $30 \mathrm{mM} \mathrm{H}_{2} \mathrm{O}_{2}$.

$>$ Tube contents mixed thoroughly by inversion. Reaction was stopped after 3 minutes with $1 \mathrm{ml}$ of $6 \mathrm{M}$ $\mathrm{H}_{2} \mathrm{SO}_{4}$.

$>7 \mathrm{ml}$ of $0.01 \mathrm{M}$ potassium permanganate $\left(\mathrm{KMnO}_{4}\right)$ added and absorbance read at $480 \mathrm{~nm}$ within $30-60$ seconds.

\subsection{Biochemical Assays of Hepatic Marker Enzymes in Plasma}

Plasma activities of hepatic marker enzymes, aspartate transaminase (AST), alanine transaminase (ALT), and alkaline phosphatase (ALP) were all assayed using kits procured from Randox Laboratories Ltd. London, United Kingdom.

\subsection{The Histology of the Liver}

Procedure:

$>$ After sacrificing the rats, the liver of each rat was dissected out, trimmed into sizes and fixed in $10 \%$ formaline for $24 \mathrm{hrs}$.

$>$ 5-6 drops of glycerol was diluted with about $10-15 \mathrm{ml}$ of water and mixed well.

$>$ A drop of this mixture was placed on a clean slide and spread evenly over the upper sides of the slide.

$>$ The upper surface of the slide was flooded with distilled water and it was thus ready for use.

$>$ Using a moist brush the specimen was put on the slide and the slide allowed to dry at a temperature of about $45-50^{\circ} \mathrm{C}$. 
$>$ Incubated at $37^{\circ} \mathrm{C}$ to dry for twelve hours and it was stained using heamatoxylene and eosine method.

$>$ The specimen was then placed properly before putting the cover slip on it, after which it was viewed under the microscope.

\subsection{Statistical Analysis of Experimental Data}

SPSS package (version 17 for Windows) was used to carry out all the statistical analyses, and the experimental data were analyzed by applying a one way Analysis of Variance (ANOVA) method to test the mean differences observed among the four groups.

\section{Results}

Table1 reports the hepatic MDA levels, SOD, and Catalase activities observed in the controls and the various treatment groups. Hepatic MDA levels increased significantly in the $\mathrm{CCl}_{4}$-treated animals over those of the Control group $(\mathrm{p}<0.05)$.

The plasma activities of hepatic marker enzymes ALT, AST, and ALP were determined in the animals, and the results are presented in Table2. Significant increases $(\mathrm{p}<0.05)$ in both ALT and ALP activities were found in the $\mathrm{CCl}_{4}$-treated animals as against those in the Control group.

The figures (1-4) clearly reveal the treatment-related histological changes observed on microscopic examination of liver tissues obtained from the rats in the various groups.

Table1. Comparison of Hepatic MDA Concentrations, SOD, and Catalase Activities among the Various

\begin{tabular}{|c|c|c|c|c|}
\hline Assay & $\begin{array}{l}1 \\
\text { Control }\end{array}$ & $\begin{array}{l}2 \\
\text { Acetaminophen Only }\end{array}$ & $\begin{array}{l}3 \\
\text { Acetaminophen+Oil }\end{array}$ & $\begin{array}{l}4 \\
\text { Moringa Oil } \\
\text { Only }\end{array}$ \\
\hline SOD (unit/mg) $\times 10^{-1}$ & $14.54 \pm 1.82^{\mathrm{a}}$ & $17.42 \pm 1.30^{\mathrm{a}}$ & $12.19 \pm 0.77^{\mathrm{a}}$ & $14.20 \pm 1.47^{\mathrm{a}}$ \\
\hline $\begin{array}{l}\text { Catalase (unit/ml) } x \\
10^{-2}\end{array}$ & $88.92 \pm 0.17^{\mathrm{a}}$ & $88.78 \pm 0.31^{\mathrm{a}}$ & $88.82 \pm 0.14^{\mathrm{a}}$ & $88.78 \pm 0.09^{\mathrm{a}}$ \\
\hline
\end{tabular}

Mean \pm Standard Error of mean, at $\mathrm{p}<0.05$

Table2. Comparison of Levels of Plasma activities of Hepatic Marker Enzymes ALT, AST, and ALP among the Various Treatment Groups.

\begin{tabular}{|lllll|}
\hline \multicolumn{1}{|c}{ Assay } & 1 Control & $\begin{array}{l}\text { 2 } \\
\text { Acetaminophen Only }\end{array}$ & $\begin{array}{l}\text { 3 } \\
\text { Acetaminophen+ Moringa } \\
\text { Oil }\end{array}$ & $\begin{array}{l}\text { 4 } \\
\text { Moringa Oil Only }\end{array}$ \\
\hline ALT (U/L) & $37.67 \pm 7.78^{\mathrm{a}}$ & $132.20 \pm 2.10^{\mathrm{b}}$ & $88.50 \pm 3.76^{\mathrm{c}}$ & $44.33 \pm 2.39^{\mathrm{a}}$ \\
AST (U/L) & $42.33 \pm 8.59^{\mathrm{a}}$ & $59.67 \pm 5.45^{\mathrm{a}}$ & $56.33 \pm 3.36^{\mathrm{a}}$ & $39.67 \pm 5.93^{\mathrm{a}}$ \\
ALP (IU/L) & $4.42 \pm 1.25^{\mathrm{a}}$ & $21.91 \pm 1.21^{\mathrm{b}}$ & $13.93 \pm 1.37^{\mathrm{c}}$ & $5.48 \pm 0.64^{\mathrm{a}}$ \\
\hline
\end{tabular}

Mean \pm Standard Error of mean, at $\mathrm{p}<0.05$

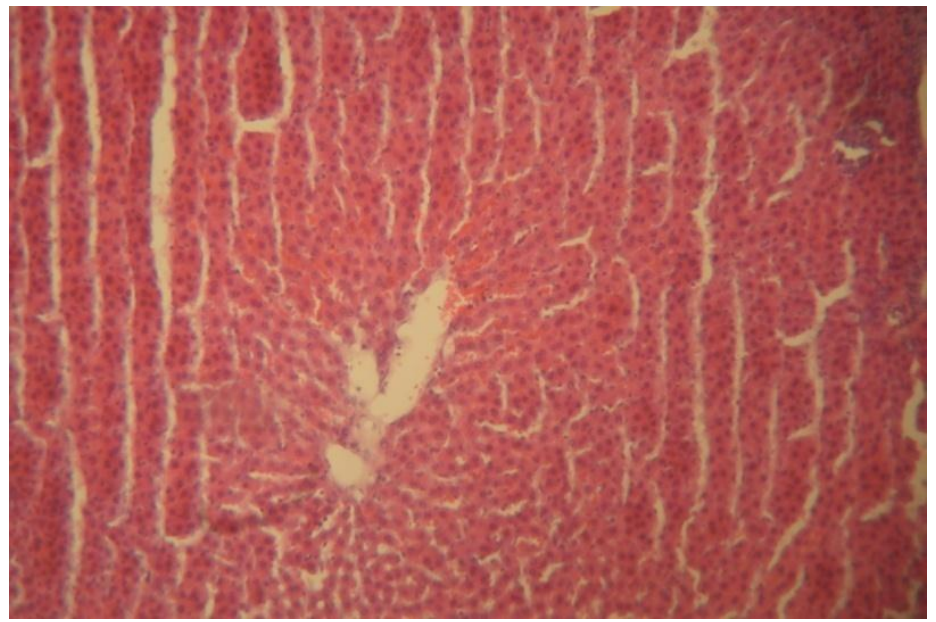

Fig 1 Control group Liver histological section: Normal histological appearance. At higher magnification (x40) the nucleus appears distinct. 


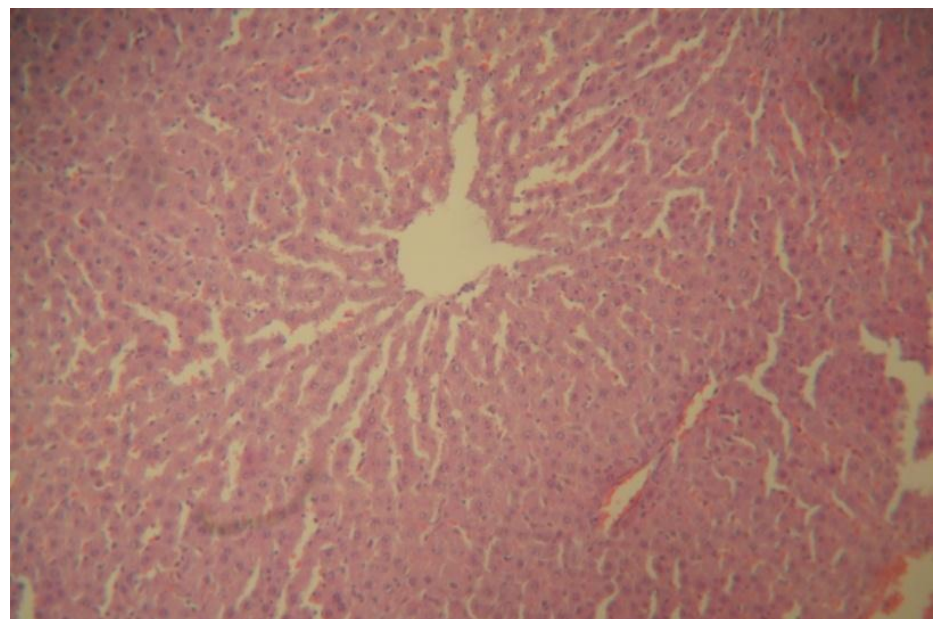

Fig 2. Acetaminophen only (Group 2): Liver histological section reveals extensive necrotic changes in the hepatocytes.

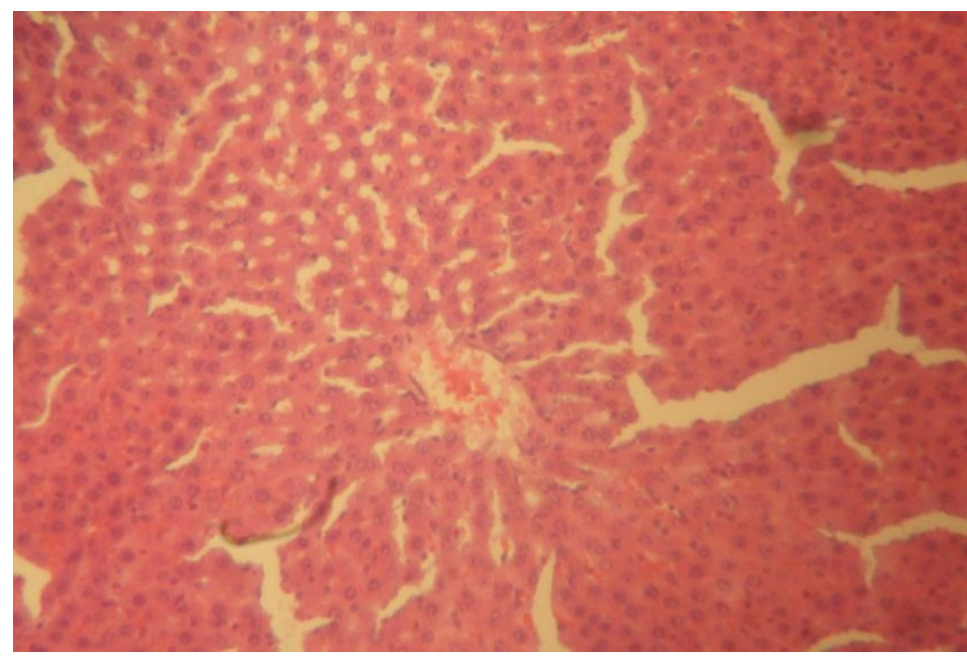

Fig 3. Acetaminophen + oil treated group: Liver section showing mildly congested venules.

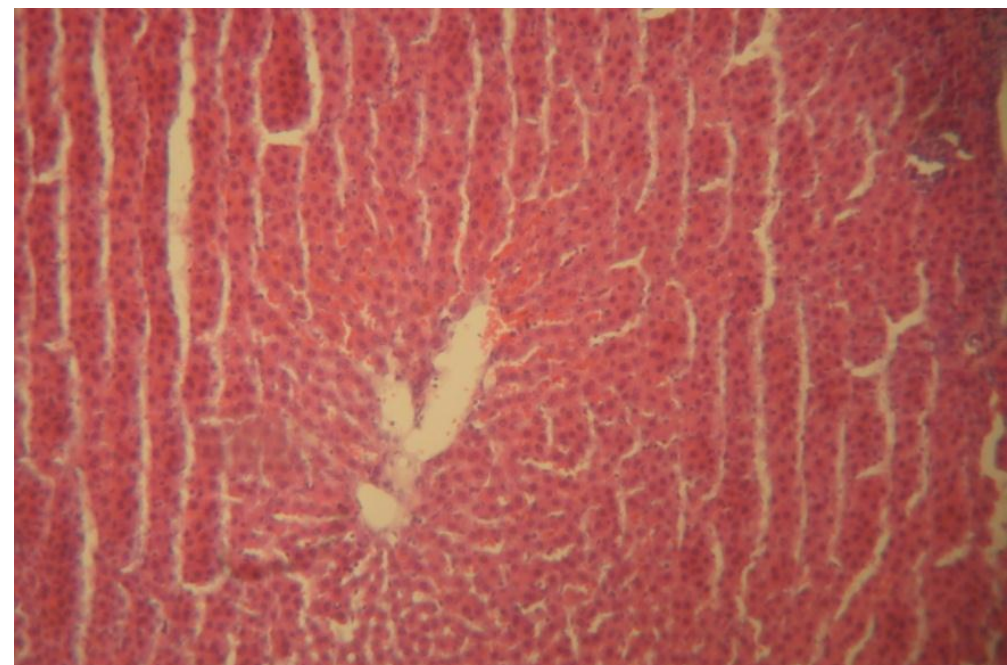

Fig 4. Moringa seed oil treated group: Liver section showing normal cellular architecture; no remarkable changes in comparison with the Control. 


\section{Discussion}

Natural remedies from traditional plants are seen as effective and safe alternative treatments for hepatotoxicity [26], especially caused by foreign agents. Studies on Moringa oleifera plant most of which were centered on the hepatoprotective activity of its leaves, flowers, roots and seeds are widely documented in literature $[8,27,28,29]$. The present study focused mainly on the medicinal effect of Moringa oleifera seed oil against acetaminophen-induced hepatotoxicity.

As reported in Table 2, significantly lower plasma ALT and ALP activities were found in animals pretreated with the Moringa oil (group 3) compared with those that received only acetaminophen (group2); this supports findings from previous studies on the Moringa oleifera plant $[11,26]$. These results however indicate the potential ability of Moringa oleifera seed oil to significantly attenuate liver injury caused by acetaminophen toxicity by protecting the integrity of liver cells, thus leading to lower levels of activity of both marker enzymes in plasma.

The liver plays a central role in the maintenance of systemic lipid homeostasis and is especially susceptible to ROS damage [26], which probably explains why hepatic MDA was significantly raised in the acetaminophen-intoxicated animals in group 2 (Table 1) compared with the animals pre-treated with Moringa oil. The observed hepatic MDA elevation in the group 2 animals (Table 1) adds to previous reports [30], and is an indication of enhanced lipid peroxidation, clearly demonstrating the hepatotoxicity of the xenobiotic acetaminophen. Liver tissue contains a relatively high content of polyunsaturated fatty acids (PUFAs), which are sensitive to peroxidative damage [31]. Moringa oleifera seed oil is therefore believed to possess a strong antioxidant effect which could help preserve the hepatocellular membrane integrity from the xenobiotic-induced damage. The consumption of this oil may provide health benefits in terms of hypocholesterolemic effects (due to the presence of phytosterols) and scavenging of free radicals in the body (due to the presence of tocopherols, phenolics and carotenoids) [32].

The various changes observed in liver tissues of the animals as revealed by histological examinations (Figures 1-4) lend considerable support to the biochemical evidences reported in this study.

\section{Conclusion}

Evidences from this study indicate that Moringa oleifera seed oil is potentially effective as a therapy in treatment of xenobiotic-induced liver disorders. It is however believed that this hepatoprotective action of the oil is mediated by its natural antioxidant components made up of tocopherols, phenolics and carotenoids.

\section{Acknowledgements}

The authors wish to thank Dr. Agoreyo (Mrs.) Mr. Sam Ojeaburu for their valuable suggestions while conducting this research.

\section{References}

[1] Singh A, Bhat TK and Sharma OP (2011). Clinical Biochemistry of Hepatotoxicity. Journal of Clinical Toxicology S: 4. http://dx.doi.org/10.4172/2161-0495.S4-001

[2] Jones AL. Anatomy of the normal liver. In: Zakin D, Boyer TD, eds. Hepatology: a textbook of liver disease, 3rd ed. Philadelphia: WB Saunders, 1996:3-32.

[3] Navarro VJ, Senior JR (2006) Drug-related hepatotoxicity. N Engl J Med 354: 731-739.

[4] Musana KA, Yale SH, Abdulkarim AS (2004). Clinical Medicine \& Research Volume 2, Number 2: 129-131. Full text articles available at: http://www.mfldclin.edu/clinmedres

[5] Teschke R (2009) Hepatotoxicity by drugs and dietary supplements: safety perspectives on clinical and regulatory issues. Ann Hepatol 8: 184-195.

[6] Greenhough S, Hay DC (2012). "Stem Cell-Based Toxicity Screening: Recent Advances in Hepatocyte Generation". Pharm Med 26 (2): 85-89.

[7] Friedman SE, Grendel JH, McQuaid KR (2003). Current diagnosis \& treatment in gastroenterology. New York: Lang Medical Books/McGraw-Hill. Pp. 664-679. ISBN 0-8385 1551-7.

[8] Fakurazi S, Nanthini U and Hairuszah I. Hepatoprotective and antioxidant action of Moringa oleifera Lam. against acetaminophen induced hepatotoxicity in rats. International Journal of Pharmacology, 4(4), 2008, 270-275.

[9] Wallace JL (2004) Acetaminophen hepatotoxicity: NO to the rescue. Br J Pharmacol 143: 1-2.

[10] Jaeschke H, Gores GJ, Cederbaum AI, Hinson JA, Pessayre D, and Lemasters JJ (2002). Mechanisms of Hepatotoxicity. TOXICOLOGICAL SCIENCES 65, 166-176.

[11] Olatosin TM, Akinduko DS, Uche CZ. Evaluation of the Hepatoprotective Efficacy of Moringa oleifera Seed Oil on Ccl4Induced Liver Damage in Wistar Albino Rats. The International Journal of Engineering and Science (IJES), Volume 2(11): 1318, 2013. ISSN (e): $2319-1813$ ISSN (p): $2319-1805$.

[12] Sturgill MG and Lambert GH (1997). Xenobiotic-induced hepatotoxicity: mechanisms of liver injury and methods of monitoring hepatic function. Clinical Chemistry 43:8(B) 1512-1526.

[13] Kaplan MM. Laboratory tests. In: Schiff L, Schiff ER, eds. Diseases of the liver, 7th ed. Philadelphia: JB Lippincott, 1993: 108-44.

[14] Kaplan MM. Serum alkaline phosphatase-another piece is added to the puzzle. Hepatology 1986;6: 526-8.

[15] Friedman LS, Martin P, Munoz SJ (1996). Liver function tests and the objective evaluation of the patient with liver disease. In: D. Zakin, T. D. Boyer (Eds.), Hepatology: a textbook of liver disease. $3^{\text {rd }}$ edition, WB Saunders, Philadelphia, pp 791-833. 
[16] James LP, Mayeux PR, and Hinson JA (2003). Acetaminophen-Induced Hepatotoxicity. Drug Metabolism and Disposition Vol. 31, No. 12. Copyright (C) 2003 by the American Society for Pharmacology and Experimental Therapeutics 1128/1106568 DMD 31:1499-1506.

[17] Nakae D, Yoshiji H, Yamamoto K, Maruyama H, Kinugasa T, Takashima Y, Denda A, and Konishi Y (1990) Influence of timing of administration of liposome-encapsulated superoxide dismutase on its prevention of acetaminophen-induced liver cell necrosis in rats. Acta Pathol Jpn 40:568-573.

[18] Cowan MM (October, 1999). Plant Products as Antimicrobial Agents. Clin. Microbiol. Rev. 12(4): 564-582

[19] Pracheta SS, Sharma V, Paliwal R, Sharma S, and Singh L et al. (2011). Chemoprotective activity of hydro-ethanolic extract of Euphorbia nerrifolia Linn. leaves against DENA-induced liver carcinogenesis in mice. Biol. Med., 3: 36-44.

[20] Mahmood KT, Mugal T, Haq IU (2010). Moringa oleifera: A natural gift- A review. J. Phar. Sci., 2: 775-781.

[21] Paliwal R, Sharma V, and Pracheta SS (2011). A review of Horse Radish Tree (Moringa oleifera): A Multipurpose Tree with High Economic and Commercial Importance. Asian Journal of Biotechnology 3 (4): 317-328

[22] Paliwal R, Sharma V, Pracheta SS, Yadav S \& Sharma SH (2011). Antinephrotoxic effect of administration of Moringa oleifera lam in amelioration of dmba-induced renal carcinogenesis in swiss albino mice. Biol. Med., 3: 25-35.

[23] Buege JA, Aust SD, 1978. Microsomal lipid, Peroxidation. In: Flesicher, S., Packer, L. (Eds.), Methods in Enzymology. Vol. 52. Academic Press, New-York, pp. 302-310.

[24] Misra HP, Fridovich I (1972). The role of superoxide anion in the autoxidation of epinephrine and a simple assay for superoxide dismutase. J Biol chem.. 247: 3170-3175

[25] Cohen G, Dembiec D, Marcus J. measurement of catalase activity in tissue extracts. Anal. Biochem. 1970; 34:30-38.

[26] Fakurazi S, Sharifudin SA, and Arulselvan P (2012). Moringa oleifera Hydroethanolic Extracts Effectively Alleviate Acetaminophen-Induced Hepatotoxicity in Experimental Rats through Their Antioxidant Nature. Molecules 2012, 17, 8334-8350; doi:10.3390/molecules17078334

[27] Alaaeldin A and Hamza. Curcuma longa, Glycyrrhiza glabra and Moringa oleifera ameliorate diclofenac - induced hepatotoxicity in rats. American Journal of Pharmacology and Toxicology, 2(2), 2007, 80-88.

[28] Ruckmani K, Kavimani P, Anandan R and Jaykar B. Effect of Moringa oleifera Lam on paracetamol - induced hepatotoxicity. Indian Journal of Pharmaceutical Sciences, 60, 1998, 33-35.

[29] Gilani AH, Janbaz KH and Shah BH. Quercetin exhibits hepatoprotective activity in rats. Biochemical Society Transactions, 25, $1997,85$.

[30] Al-Said MS, Mothana RA, Al-Yahya MA, Al-Blowi AS, Al-Sohaibani M, Ahmed AF, Rafatullah S. Edible Oils for Liver Protection: Hepatoprotective Potentiality of Moringa oleifera Seed Oil against Chemical-Induced Hepatitis in Rats. Journal of Food Science, Volume 77, Issue 7, pages T124-T130, July 2012. DOI:10.1111/j.1750-3841.2012.02698.x

[31] Catala A. Lipid peroxidation of membrane phospholipids generates hydroxy-alkenals and oxidized phospholipids active in physiological and/or pathological conditions. Chemistry and Physics of Lipids. 2009; 157: 1 - 11

[32] Bhatnagar AS and Krishna AGG Natural antioxidants of the Jaffna variety of Moringa Oleifera seed oil of Indian origin as compared to other vegetable oils. Grasas Y Aceites, 64 (5), octubre-diciembre, 537-545, 2013, issn: 0017-3495 doi: $10.3989 /$ gya.010613 